\title{
AN UNUSUAL ATRIAL RHYTHM WITH VARYING A-V BLOCK
}

\author{
BY \\ C. P. ABER* \\ From the Liverpool Royal Infirmary
}

The following report concerns a most unusual type of supraventricular rhythm associated with a variation in $\mathrm{A}-\mathrm{V}$ conduction, in an apparently normal heart. It is believed that no similar case has hitherto been reported.

The occurrence of paroxysmal supraventricular tachycardia with A-V block is well known. In 1909 Sir Thomas Lewis demonstrated this type of arrhythmia with a polygraph (1925). In 1925 Sprague and White reported three further cases in their review of 56 patients with paroxysmal tachycardia: one of these had A-V block that varied between from $1: 1,3: 2,2: 1$, or $3: 1$, with atrial rates of 200-270 a minute and there seemed no relationship between the atrial rate and degree of block observed. A further case in their series had A-V block of the Wenckebach type appearing only after exercise. Geraudel (1937) reported a 63-year-old man whom he had observed for five years with varying supraventricular tachycardia; he at times showed 2:1 block or a Wenckebach type of block with an atrial rate of 172 a minute. Maddox (1937) studied a patient with a persistent atrial rate of 160 a minute and demonstrated the effects of carotid sinus compression and intravenous digoxin in producing a Wenckebach type of block; he also noted the effects of postural changes on this type of tachycardia, producing a reduction of the ventricular rate to 56 a minute, with a 3:1 block, by putting the patient in a recumbent position.

Parkinson and Papp (1947) collected 40 cases of "repetitive paroxysmal tachycardia," 16 of which showed the supraventricular type of rhythm with atrial rates of 160-300 a minute; in seven of these, varying degrees of A-V block were present. Scherf and Harris (1946) described 31 cases of "coronary sinus rhythm," in which the P wave of the sinus beat suddenly changed to an abnormal form without any change in the rate. The diagnosis of this type of rhythm depends upon the presence in leads II and III of $P$ waves that are inverted and often sharply peaked: the $\mathbf{P}-\mathrm{R}$ interval is usually normal or less than normal. No case with A-V block was observed in their series.

That all varieties of supraventricular rhythm may exist, either at the same time or at varying times in the same patient, is now well proven, and there is ample evidence that these arrhythmias depend on a similar mechanism of production, reflecting the presence and behaviour of ectopic irritable atrial foci. Fig 1 reveals this type of variation in the same subject. Paroxysmal supraventricular tachycardia with or without conduction block is alleged to occur most frequently in the absence of organic heart disease, or as the result of administration of digitalis in heart disease (Geraudel, 1937; Barker et al., 1943; Spritz et al., 1958). Decherd et al. (1943) believed that the presence of such a tachycardia with A-V block indicated underlying myocardial damage in most instances. In reviewing 40 patients with this type of arrhythmia they found only two cases in which there appeared to be no pathological heart lesion: both, however, had received varying quantities of digitalis prior to the onset of the conduction block. In repetitive supraventricular tachycardia, no evidence of organic heart disease was observed (Parkinson and Papp, 1947). With coronary sinus rhythm the presence of ischæmic or hypertensive heart disease is common (Scherf and Harris, 1946).

* At present Senior Medical Registrar, Thoracic Unit, Broadgreen Hospital, Liverpool. 


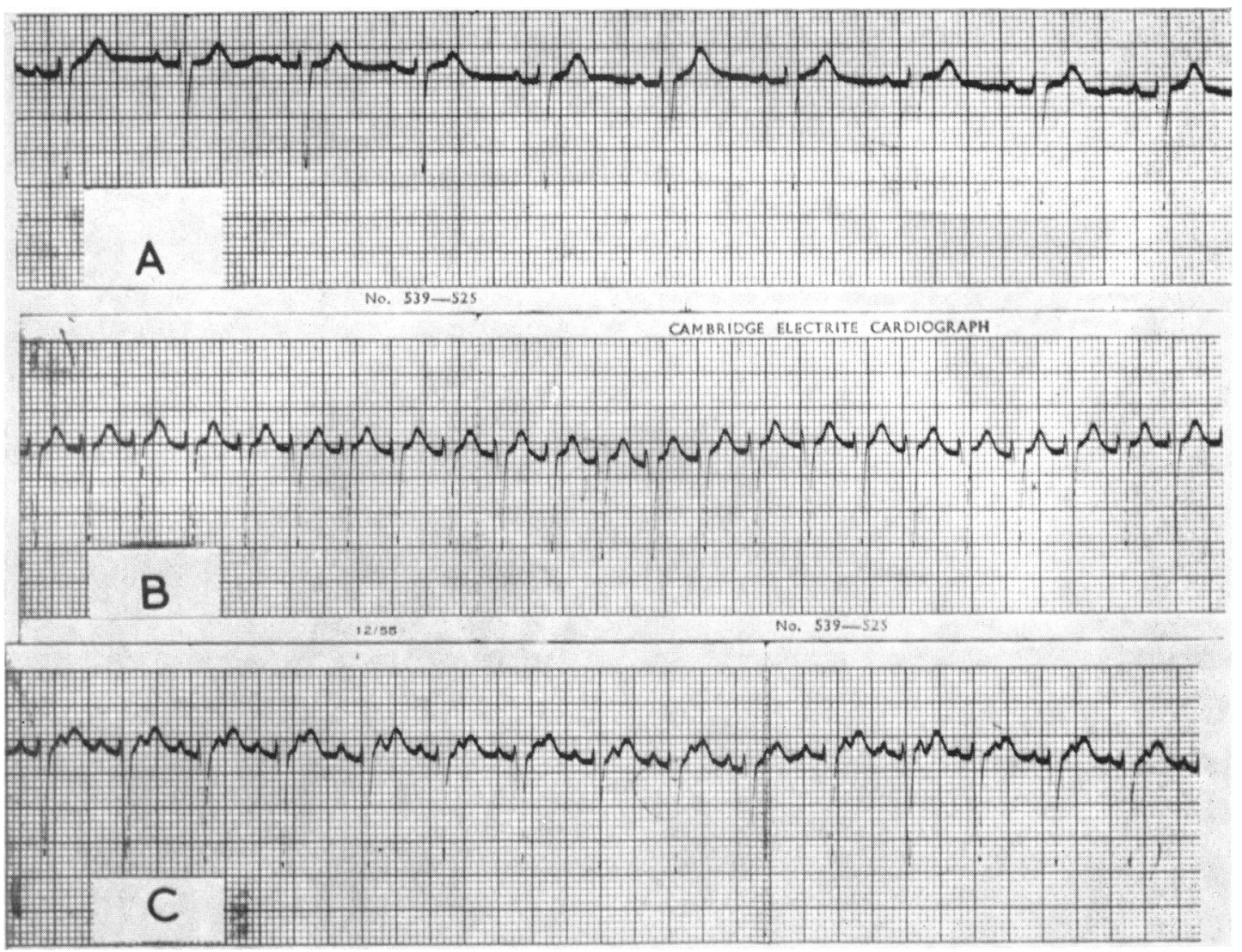

FIG. 1.-(A) Normal rhythm; (B) paroxysmal tachycardia without conduction block; (C) paroxysmal tachycardia with 2:1 A-V block.

\section{Case Report}

A 23-year-old East African was observed on routine medical examination to have a grossly irregular pulse. There was no history of previous or recent ill health, nor was he known to have received either "herbs" or medications. He had been a first-class athlete all his life and when examined was completely symptom free.

Clinical examination showed an apparently healthy and well-nourished young man. Cardiovascular examination confirmed the presence of a grossly irregular peripheral pulse, which varied in both rhythm and rate during the course of the examination, phases of regular rhythm at 75 a minute alternating with phases of relative tachycardia (100-104 a minute) during which dropped beats were periodically observed. Isolated " $a$ " waves were sometimes visible in his jugular venous pulse, these coinciding with a phase of relative tachycardia, and preceding each dropped beat. There were no clinical signs of cardiac enlargement and the apical impulse was normal. No evidence of heart failure was present. The quality of the first heart sound varied during the phases of relative tachycardia, and at times, also during a period of tachycardia, a mid-diastolic triple rhythm appeared; on other occasions, despite this relative tachycardia, no such sound was audible, and at these times the dropped beats were more frequent. Carotid compression seemed to decrease the frequency of the intermissions, without affecting the rate appreciably. The blood pressure was 140/75. No other abnormalities were detected in the cardiovascular, respiratory, alimentary, and central nervous systems.

Clinical interpretation of this arrhythmia was difficult, but the presence of isolated " $a$ " waves and the changing quality of the first heart sound in association with the dropped beats made the diagnosis of Wenckebach phenomenon seem likely. To study this arrhythmia a continuous electrocardiographic record was taken during one examination (Fig. 2). 


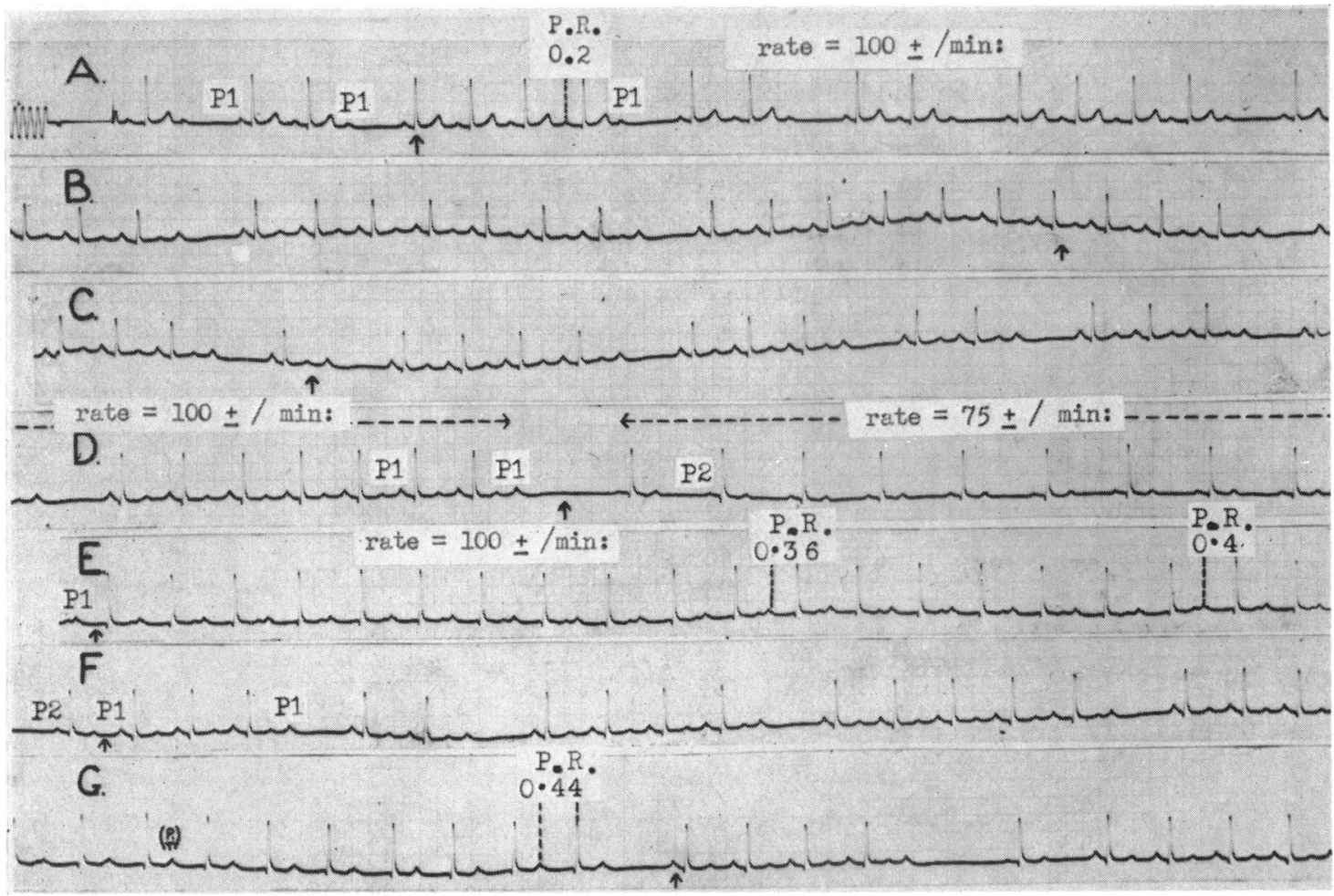

FIG. 2.-All traces standard lead II. (A) shows a Wenckebach type of block with P-R intervals $0 \cdot 12-0 \cdot 2$ sec. at an atrial rate of $100 \pm 14$ a minute with bifid $P$ waves (P1); (B) and (C) the effects of carotid compression (between arrows); (D) demonstrates an abrupt change of rhythm $(\uparrow)$ to a regular sinus pattern (rate 75 a minute) with normal $P$ waves (P2) and a constant $P-R$ interval 0.15 sec.; (E) return of the abnormal atrial rhythm with the P-R interval increasing to $0.4 \mathrm{sec}$. without dropped beats (rate 100 a minute); (F) further rhythm change ( $\uparrow$ ) from the normal sinus to the atrial rhythm, with return of the Wenckebach type of block at a maximum $\mathbf{P}-\mathbf{R}$ interval of $0.2 \mathrm{sec}$.; (G) the $\mathbf{P}$ waves (P1) and the preceding $T$ waves are submerged, with prolongation of $\mathbf{P}-\mathbf{R}$ interval (0.4-0.44 sec.) (at which time the triple rhythm was evident). Later there is a return of the Wenckebach block and decrease in the P-R interval (with disappearance of the triple rhythm). No significant effects resulted from exercise, postural changes, atropine, quinidine, or digitalis administration.

The following investigations were made and all gave normal or negative results. Full blood count, erythrocyte sedimentation rate (Westergren), serum W. R. and Kahn reactions, gonococcal complement fixation test, Widal agglutination reactions, toxoplasmosis and histoplasmosis complement fixation, plasma proteins, and electrophoretic pattern. No L.E. cells were seen in the peripheral blood. X-ray films and radiographic examinations of the chest and heart gave normal results.

\section{Comment}

The electrocardiograms reveal a paroxysmal abnormal atrial rhythm with a marked variation in A-V block. The features of special interest in this case are (i) that an abnormal atrial arrhythmia was present in association with varying grades of A-V block in the absence of evidence of organic heart disease; (ii) that this arrhythmia should exist with an atrial rate as low as $90-100$ a minute, which is unusual, though short runs of paroxysmal atrial tachycardia at this rate are described (Prinzmetal et al., 1952), but not with an accompanying A-V block; (iii) that contrary to the described effects of carotid sinus compression in A-V block, namely, of increasing or inducing such a block (Wood, 1957), here the effect was the reverse (Cordeiro, 1953); (iv) furthermore, no change in rhythm was observed with exercise, atropine, etc., unlike the findings in coronary sinus rhythm (Scherf and Harris, 1946). 
The particular interest in this case is that in a patient with a changing heart rhythm (but without an appreciable tachycardia) phases occurred during which the presence of isolated " $a$ " waves in the jugular venous pulse in association with dropped beats suggested the presence of a Wenckebach block; further, at other times (again without appreciable change in rate) these signs disappeared and a mid-diastolic triple rhythm became audible, suggesting a summation gallop. These physical signs may also suggest the finding of gross prolongation of the P-R interval with submergence of the $\mathbf{P}$ waves in the preceding $T$ waves in the electrocardiogram.

\section{Summary}

An account is given of an exceptional arrhythmia, the parallel of which has not hitherto been recorded, as far as is known. The arrhythmia occurred in an apparently normal heart and revealed a pattern of heart activity that was considered to lie somewhere between that of repetitive paroxysmal supraventricular tachycardia and coronary sinus rhythm.

\section{References}

Barker, P. S., Wilson, F. N., Johnston, F. D., Arbor, A., and Wishart. S., (1943). Amer. Heart J., 25, 765.

Cordeiro, A. (1953). Amer. Heart J., 46, 460.

Decherd, G. M., Herrmann, G. R., and Schwab, E. M. (1943). Amer. Heart J., 26, 446.

Gendel, B. R. (1947). Amer. Heart J., 34, 722.

Geraudel, E. (1937). Arch. Mal. Coeur, 30, 976.

Lewis, T. (1925). The Mechanisms and Graphic Registration of the Heart Beat. London, Shaw \& Sons, p. 240 et seq. Maddox, K. (1937). Amer. Heart J., 14, 183.

Parkinson, J., and Papp, C. (1947). Brit. Heart J., 9, 241.

Prinzmetal, M., Corday, E., Brill, K., Obrath, R. W., Kruger, M. E., and Fields, J. (1952). The Auricular Arrhythmias. Springfield, Charles C. Thomas.

Scherf, D., and Harris, R. (1946). Amer. Heart J., 32, 443.

Sprague, H. B., and White, P. D. (1925). Med. Clin. N. America., 8, 1855.

Spritz, N., Frimpter, G. L., Braveman, W. S., and Rubin, A. L. (1958). Amer. J. Med., 25, 442.

Wood, P. (1957). Diseases of the Heart and Circulation. Eyre and Spottiswoode, London, p. 133. 